\title{
Regional flow duration curves for ungauged sites in Sicily
}

\author{
F. Viola, L. V. Noto, M. Cannarozzo, and G. La Loggia \\ Dipartimento d'Ingegneria Idraulica ed Applicazioni Ambientali, Università degli Studi di Palermo, Palermo, Italia
}

Received: 5 August 2010 - Published in Hydrol. Earth Syst. Sci. Discuss.: 20 September 2010

Revised: 3 January 2011 - Accepted: 10 January 2011 - Published: 25 January 2011

\begin{abstract}
Flow duration curves are simple and powerful tools to deal with many hydrological and environmental problems related to water quality assessment, water-use assessment and water allocation. Unfortunately the scarcity of streamflow data enables the use of these instruments only for gauged basins. A regional model is developed here for estimating flow duration curves at ungauged basins in Sicily, Italy. Due to the complex ephemeral behavior of the examined region, this study distinguishes dry periods, when flows are zero, from wet periods using a three parameters power law to describe the frequency distribution of flows. A large dataset of streamflows has been analyzed and the parameters of flow duration curves have been derived for about fifty basins. Regional regression equations have been developed to derive flow duration curves starting from morphological basin characteristics.
\end{abstract}

\section{Introduction}

One of the most commonly used tools in hydrology is the flow duration curve (FDC), which provides a graphical representation of the frequency distribution of the complete flow regime of a catchment. Using the FDC, it is possible to estimate the percentage of time that a specified streamflow is equaled or exceeded. This type of information is commonly used for resource assessments including hydropower design schemes, water supply, planning and design of irrigation systems and water quality assessment with applications to stream-pollution and the evaluation of river habitats. Vogel and Fennessey (1995) presented a comprehensive review of FDC applications in water resources planning and management.

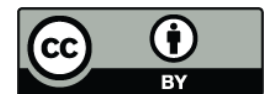

Correspondence to: F. Viola (viola@idra.unipa.it)
There are two interpretations of FDC: the traditional is reported in literature as period-of-record FDC, while the second, introduced by Vogel and Fennessey (1994), refers to annual interpretation of FDC (AFDC). In the first approach (Smakhtin, 2001) FDC consists of the complement of the cumulative distribution function of the daily streamflows over the whole available period of records. The second approach considers FDCs for individual years, using only the hydrometric information collected in a calendar or water year. Vogel and Fennessey (1994) illustrated how to derive for gauged river basins (a) the median AFDC, which represents the distribution of streamflows in a median hypothetical year and is not affected by the observation of abnormally wet or dry periods during the period of record, (b) the confidence intervals around the median FDC, summarizing the observed inter-annual variability of streamflows, (c) the AFDC associated with a given recurrence interval.

A FDC can be easily derived from gauged river flow data at daily or monthly time scale. The data are ranked in descending order and each ordered value is associated with an exceedance probability, for example through a plotting position formula. The lack of streamgauges and the limited amount of streamflow observations characterize several geographical areas around the world and, from this point of view, Sicily is not an exception. This condition led to the formulation and proposal of numerous procedures for regionalizing FDC, whose aim is the estimation of FDC at ungauged river basins or the enhancement of empirical FDC derived for streamgauges where only a limited amount of hydrometric information is available. A rough classification of the available regionalization procedures distinguishes two approaches: statistical and parametric. The first procedure considers FDC as the complement of the cumulative frequency distribution of streamflows, while the second one does not make any connection between FDC and the probability theory (Castellarin et al., 2004). 
The statistical procedures use stochastic models to represent FDC. In this case a suitable probability distribution is chosen as the parent distribution for a particular region and the distribution parameters are estimated on a local basis for the gauged river basins located in the study region using the streamflow observations. Ganora et al. (2009) observed that theoretically FDC could not be interpreted as a probability curve since discharge is correlated between successive time intervals and discharge characteristics are dependent on the season. However the FDC is often interpreted as probability distribution and the most used distribution is the log-normal, which has been proposed by Beard (1943) and successfully used by several authors (Fennessey and Vogel, 1990). Other authors used different distributions as the beta (Iacobellis, 2008) or the kappa (Castellarin et al., 2007). The use of complex distributions with more than two parameters is often justified by the greater flexibility that they offer in the representation of the runoff frequency regime. Castellarin et al. (2007) for example observed that in the $L$ moment ratios diagram the sample L-skewness and L-kurtosis for the empirical series of dimensionless daily streamflows are evenly scattered over a finite portion of the diagram. This condition cannot be adequately interpreted by a single two or three parameter distribution while it is manageable with the four parameter kappa distribution.

After the distribution choice, regional regression models are then identified for predicting the distribution parameters at ungauged basins on the basis of geo-morphological and climatic characteristics of the basins.

In the parametric approach the representation of the FDC is achieved by analytical relationships. The parameters of the relationships for ungauged river basins can be then estimated through regional models, in the same way as the parameters of the parent distribution for the statistical approaches are linked to morpho-climatic data.

There are numerous examples in the literature of regional models for estimating the FDC from relationships between these measures and physical characteristics of a catchment. Often these studies regard large catchments with perennial streamflows, as Canada (Leboutillier and Waylen, 1993), India (Singh et al., 2001), Italy (Castellarin et al., 2007; Castellarin et al., 2004; Franchini and Suppo, 1996; Iacobellis, 2008; Ganora et al., 2009), Greece (Niadas, 2005), Taiwan (Yu et al., 2002), Philippines (Quimpo et al., 1983), South Africa (Smakhtin et al., 1997) and United States (Fennessey and Vogel, 1990). It is important to point out that analysis of FDC for small catchments with ephemeral streamflows, as in Portugal (Croker et al., 2003) are less frequent than studies for perennial streamflows. Nevertheless small catchments are often of great interest for the development of local water resources especially when exploited by diversions to integrate larger water management systems.

This paper describes a regional model to derive period of record FDCs in Sicily where catchments are relatively small and often characterized by ephemeral streamflows. The

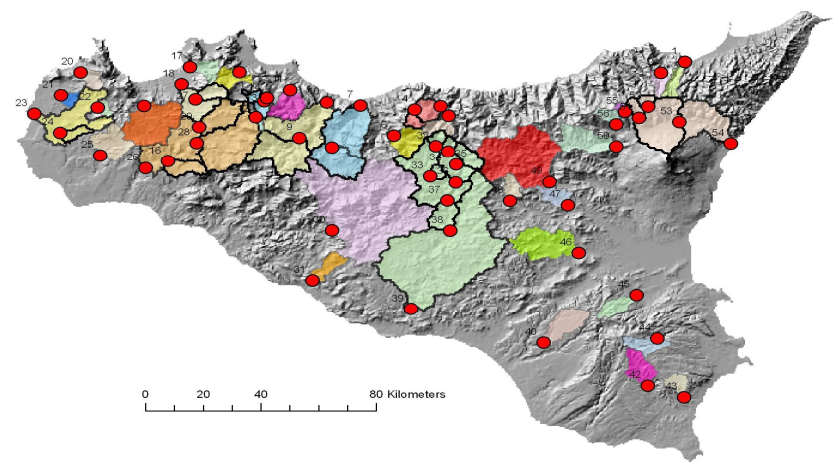

Fig. 1. Catchments location: the red dots indicate the position of streamgauges while the thick black lines are used to delineate the nested basin.

model has been developed using a data set of gauged streamflow records for 53 catchments, most of which contain significant periods of zero flow values. The model combines a simple model for predicting the percentage of time the river is wet (or dry) with a model for predicting a FDC for the non-zero period using the parametric approach. FDCs are described using a three parameters power law, which has been fitted on all the available time series. The model parameters have been then related to morphological basin characteristics, developing three sets of regional regression equations for the three homogeneous sub-areas individuated over the whole study region.

\section{Study area and dataset}

This study has been carried out for the catchments of the largest island in the Mediterranean Sea, Sicily, which extends over an area of $25700 \mathrm{~km}^{2}$. The mean annual rainfall over the island is about $715 \mathrm{~mm}$ (period 1921-2004); precipitations are concentrated in the winter period while the July-August months are usually rainless.

Daily streamflows have been provided for the study by OA-ARRA (Osservatorio delle Acque - Agenzia Regionale per $i$ Rifiuti e le Acque). The working period of most gauging sites starts in the middle ' 50 since only few stations give runoff data previous to this year. This fact suggested the opportunity to limit the analysis to the 43 -years period ranging from 1955 to 1997 . Only unregulated basins with at least ten years of data have been examined, reducing the number of stations used in this study to 53. For these basins the mean daily streamflows ranges from 0.04 to $7.6 \mathrm{~m}^{3} \mathrm{~s}^{-1}$; the maximum record length is 43 years (Oreto at Parco) while the mean sample size is about 20 years.

Catchment areas of these sites (Fig. 1) range from $10 \mathrm{~km}^{2}$ (Eleuterio at Lupo) to $1782 \mathrm{~km}^{2}$ (Imera Meridionale at Drasi). The average annual precipitation varies between $450 \mathrm{~mm}$ in the South-West up to more than $1100 \mathrm{~mm}$ reached 


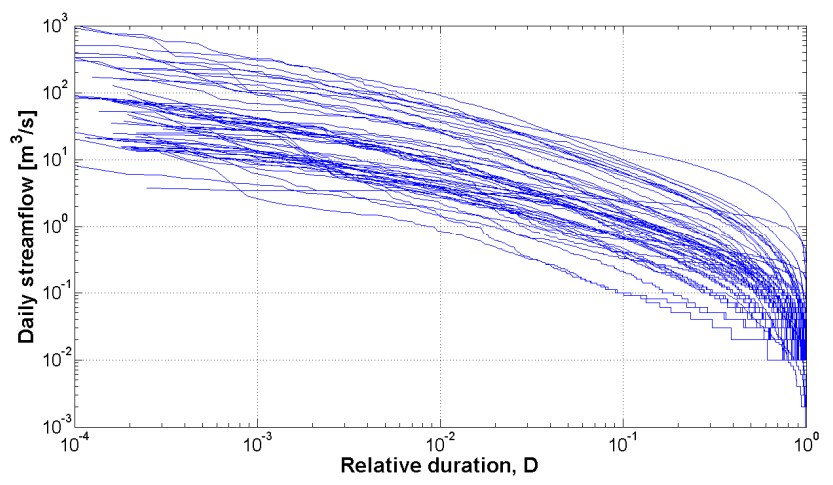

Fig. 2. Empirical flow duration curves from non-zero flows.

in the North-East of the island and the catchments have a mean elevation varying from $113 \mathrm{~m}$ up to $1474 \mathrm{~m}$ a.s.1.. The percentage of permeable area, which is a good proxy of basin geology, comprises almost all the possible conditions, from $3 \%$ to $94 \%$. Curve Number values (SCS, 1972), describing land cover and hydrologic soil properties, vary from 56 to 84 .

The most of the catchment characteristics used in this study comes directly from a GIS based tool called SIRI (Sistema Informativo Regionale Idrologico - Hydrological Regional Information System) (Noto et al., 2001; Castrogiovanni et al., 2005; Noto and La Loggia, 2009) or is easily derivable within it. After a preliminary analysis which involved about 40 characteristics, the following ones have been considered in this study: the basin area $(\mathrm{Ar})\left[\mathrm{km}^{2}\right]$, the mean areal annual precipitation $(R),[\mathrm{mm}]$, the average basin elevation $(\mathrm{Hm}),[\mathrm{m}]$, the mean areal value of Curve Number $(\mathrm{CN})$, $[-]$, the percentage of permeable area (\%perm) [-]. Following Thornthwaite (1948) the Aridity Index (AI) has been calculated as well. Table 1 shows relevant morpho-climatic catchment characteristics used in this study.

\section{Methodology}

Considering that several Sicilian catchments are ephemeral, the proposed model has to distinguish between wet periods, in which flows are different from zero, and dry periods, when flow is absent. For each gauged catchment used in the study, the relative duration of wet periods, $D_{\mathrm{w}}$, can be easily calculated starting from streamflow data as the ratio between the number of days with non-zero streamflow and the total number of days considered in the analysis.

Once $D_{\mathrm{w}}$ has been obtained it is possible to focus the attention on the non-zero streamflow historical series. The observed positive streamflows are ranked to produce a set of ordered streamflows $Q_{\mathrm{obs}, i}, i=1,2, \ldots, N$, where $N$ is the sample length. Each ordered observation $Q_{\mathrm{obs}, i}$, has been then plotted against its relative duration obtaining the empir- ical FDC for wet periods:

$$
D\left(Q_{\mathrm{obs}, i}\right)=1-\frac{i}{N+1}
$$

The empirical FDC derived from the non-zero flow data $\left(\mathrm{EFDC}_{\mathrm{nz}}\right)$ for the study catchments in Sicily are presented in Fig. 2, plotted on log-axes. One can observe that $\mathrm{EFDC}_{\mathrm{nz}}$ 's are step functions for very small non-zero streamflows as consequence of typical rounding errors for low streamflows.

The $\mathrm{EFDC}_{\mathrm{nz}}$ 's plotted on lognormal probability paper are not approximated through a straight line, pointing out that the lognormal distribution does not represent a suitable parent distribution for daily streamflow in the Sicilian catchments contrary to the most of previous studies cited in the introduction. Several other distributions have been tested but none of those was satisfactory and for this reason the stochastic approach has been discarded in favor of the parametric approach.

In order to represent $\mathrm{FDC}_{\mathrm{nz}}$ 's during wet periods a two parameters power relationship has been chosen, as follows:

$Q\left(D^{*}\right)=a\left(\frac{1-D^{*}}{D^{*}}\right)^{b}$

where $D^{*}$ is the relative duration during wet periods. The parameters $a$ and $b$ can be estimated using the least square errors method in the range of relative duration between 0.05 and 1.

The proposed FDC can be viewed as an integration of information coming from the dry and wet periods. The first are characterized by zero streamflow with relative duration (1- $\left.D_{\mathrm{w}}\right)$, while the streamflows during the wet periods, which last $D_{\mathrm{w}}$, are fully described by Eq. (2). Trying to merge these periods, FDC can be rewritten over the whole range of durations using this simple relation:

$Q(D)= \begin{cases}a\left(\frac{D_{w}}{D}-1\right) b & 0 \leq D \leq D_{\mathrm{w}} \\ 0 & D_{\mathrm{w}}<D \leq 1\end{cases}$

where $D$ is the relative duration during the whole year and $a$ and $b$ are the same parameters of Eq. (2). The above equation rescales the $\mathrm{FDC}_{\mathrm{nz}}$ on the interval [0.05: $D_{\mathrm{w}}$ ], which is the wet period, and gives $Q=0$ in dry periods.

The three model parameters ( $D_{\mathrm{w}}, a$ and $b$ ) have been estimated on 50 basins while the remaining three basins have been hidden for validation purposes. From Eq. (3) it is clear that the model is able to deal both with ephemeral or perennial streamflows. Here two FDCs, one ephemeral and one perennial, computed using the proposed procedure are presented to describe the model potentialities. The results shown in Fig. 3 point out the different hydrological regime between "Senore at Finocchiara" basin (a), with ephemeral streamflows, and the "Oreto at Parco" basin (b), which instead has continuous streamflows. The same figure shows a good fit between empirical and estimated FDCs in both ephemeral and perennial conditions for the range of durations 
Table 1. Catchments characteristics. The catchments used for the validation are bolded.

\begin{tabular}{|c|c|c|c|c|c|c|c|}
\hline & Catchment & $\operatorname{Ar}\left[\mathrm{Km}^{2}\right]$ & $R[\mathrm{~mm}]$ & $\%$ perm & $\mathrm{CN}$ & $H m[\mathrm{~m}]$ & $\mathrm{AI}$ \\
\hline 1 & Alcantara at Alcantara & 570 & 986 & 43 & 69.99 & 920 & 4.46 \\
\hline 2 & Alcantara at Mojo & 342 & 874 & 46 & 68.72 & 1142 & 3.83 \\
\hline 3 & Alcantara at San Giacomo & 25 & 994 & 16 & 69.00 & 1230 & 3.39 \\
\hline 4 & Anapo at San Nicola & 82 & 671 & 88 & 69.21 & 634 & 5.70 \\
\hline 5 & Asinaro at Noto & 55 & 600 & 90 & 75.51 & 369 & 6.42 \\
\hline 6 & Baiata at Sapone & 29 & 475 & 5 & 84.82 & 113 & 6.81 \\
\hline 7 & Belice at Sparacia & 116 & 690 & 27 & 82.22 & 555 & 6.27 \\
\hline 8 & Belice at Ponte Belice & 807 & 678 & 30 & 78.88 & 467 & 6.25 \\
\hline 9 & Belici at Bruciato & 131 & 597 & 60 & 76.00 & 625 & 5.98 \\
\hline 10 & Belici at Marianopoli Scalo & 226 & 523 & 40 & 76.00 & 606 & 6.51 \\
\hline 11 & Birgi at Chinisia & 293 & 494 & 27 & 80.68 & 194 & 6.63 \\
\hline 12 & Cassibile at Manghisi & 60 & 658 & 89 & 76.00 & 556 & 3.25 \\
\hline 13 & Castelbuono at Ponte Vecchio & 99 & 808 & 41 & 73.63 & 896 & 5.02 \\
\hline 14 & Castello at Castello & 26 & 516 & 66 & 76.00 & 655 & 5.53 \\
\hline 15 & Chitarra at Rinazzo & 37 & 480 & 49 & 80.18 & 170 & 6.71 \\
\hline 16 & Eleuterio at Lupo & 10 & 797 & 42 & 73.47 & 826 & 4.96 \\
\hline 17 & Eleuterio at Risalaimi & 53 & 810 & 43 & 76.05 & 631 & 5.44 \\
\hline 18 & Elicona at Falcone & 54 & 897 & 79 & 70.18 & 710 & 4.85 \\
\hline 19 & Fastaia at Lachinea & 23 & 566 & 28 & 79.32 & 313 & 6.29 \\
\hline 20 & Ficuzza at San Pietro & 128 & 537 & 94 & 76.67 & 369 & 6.38 \\
\hline 21 & Flascio at Zarbata & 31 & 983 & 27 & 67.13 & 1292 & 3.32 \\
\hline 22 & Fiume freddo at Alcamo scalo & 273 & 619 & 40 & 81.32 & 253 & 6.86 \\
\hline 23 & Ganci at Regiovanni & 61 & 613 & 51 & 80.76 & 856 & 4.89 \\
\hline 24 & Imera Merid. at Cinque archi & 545 & 680 & 17 & 80.17 & 726 & 5.33 \\
\hline 25 & Imera Merid. at Capodarso & 631 & 660 & 3 & 80.07 & 690 & 5.46 \\
\hline 26 & Imera Merid. at Drasi & 1782 & 552 & 28 & 78.91 & 586 & 5.93 \\
\hline 27 & Imera Merid. at Petralia & 28 & 835 & 63 & 75.46 & 1231 & 3.96 \\
\hline 28 & Imera Merid. at ponte Besaro & 995 & 652 & 27 & 79.00 & 632 & 5.02 \\
\hline 29 & Imera Sett. at Scillato & 105 & 712 & 35 & 76.64 & 829 & 5.26 \\
\hline 30 & Isnello at Ponte Grande & 33 & 888 & 52 & 69.52 & 1187 & 4.24 \\
\hline 31 & Jato at Fellamonica & 49 & 828 & 43 & 78.91 & 480 & 6.01 \\
\hline 32 & Martello at Petrosino & 43 & 935 & 22 & 65.07 & 1300 & 3.46 \\
\hline 33 & Milicia at Milicia & 112 & 618 & 34 & 81.05 & 485 & 5.82 \\
\hline 34 & Nocella at Zucco & 57 & 900 & 67 & 74.11 & 540 & 6.11 \\
\hline 35 & Oreto at Parco & 76 & 1036 & 67 & 73.85 & 608 & 5.76 \\
\hline 36 & Platani at Passofonduto & 1186 & 611 & 25 & 79.87 & 525 & 6.03 \\
\hline 37 & San Biagio at Mandorleto & 74 & 545 & 15 & 82.83 & 351 & 6.46 \\
\hline 38 & Salso at Monzanaro & 184 & 604 & 21 & 80.85 & 786 & 5.07 \\
\hline 39 & Salso at Raffo & 21 & 761 & 33 & 80.43 & 1062 & 4.30 \\
\hline 40 & Saraceno at Chiusitta & 19 & 1117 & 19 & 65.70 & 1474 & 2.98 \\
\hline 41 & Sciaguana at Torricchia & 67 & 449 & 24 & 78.48 & 414 & 6.20 \\
\hline 42 & Senore at Finocchiara & 77 & 652 & 22 & 79.20 & 422 & 6.32 \\
\hline 43 & San Leonardo at Monumentale & 521 & 705 & 9 & 79.33 & 578 & 5.65 \\
\hline 44 & San Leonardo at Vicari & 253 & 707 & 10 & 80.13 & 672 & 5.37 \\
\hline 45 & Salso at Ponte Gagliano & 499 & 634 & 39 & 79.90 & 794 & 5.04 \\
\hline 46 & Tellaro at Castelluccio & 102 & 573 & 74 & 72.81 & 452 & 6.33 \\
\hline 47 & Timeto at Murmari & 50 & 964 & 79 & 75.15 & 724 & 4.67 \\
\hline 48 & Torrente Mulini at Guglielmotto & 61 & 887 & 41 & 72.93 & 1157 & 4.17 \\
\hline 49 & Torto at Bivio Cerda & 414 & 535 & 28 & 80.39 & 491 & 6.32 \\
\hline 50 & Torto at Roccapalumba scalo & 173 & 482 & 32 & 80.65 & 565 & 5.97 \\
\hline 51 & Trigona at Rappis & 72 & 593 & 90 & 56.13 & 465 & 6.25 \\
\hline 52 & Troina at Serravalle & 157 & 655 & 23 & 79.80 & 1025 & 4.43 \\
\hline 53 & Valle acqua at Serena & 22 & 819 & 83 & 74.38 & 638 & 5.41 \\
\hline
\end{tabular}



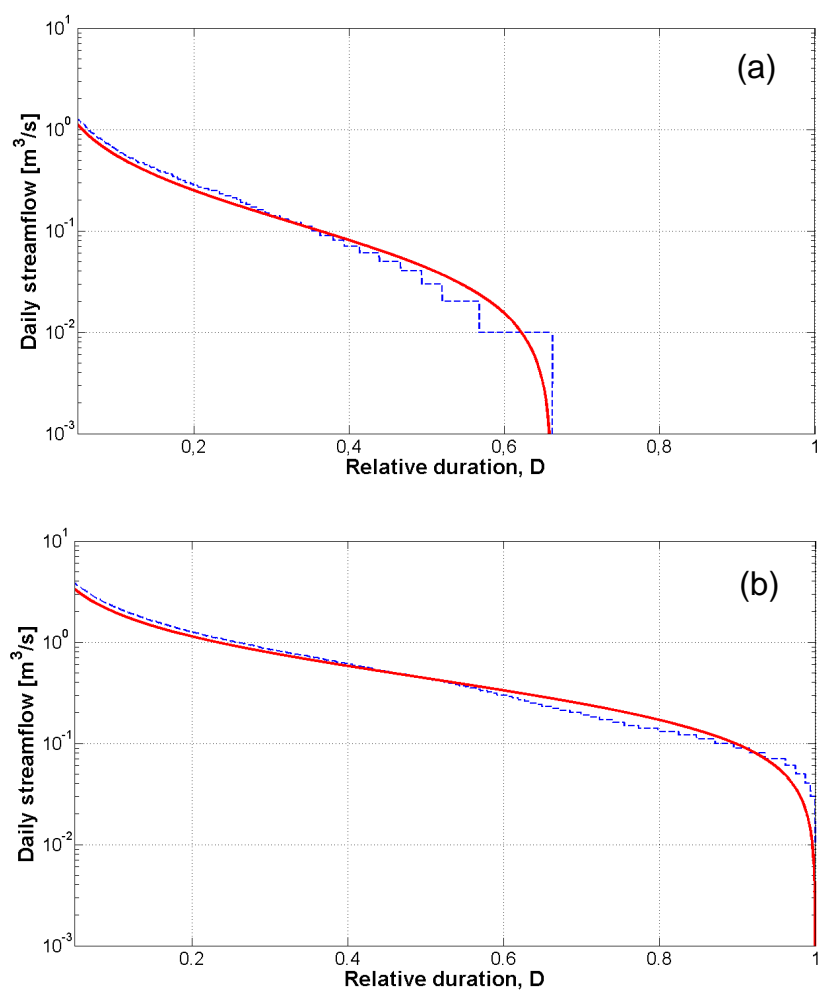

Fig. 3. Empirical (line) and estimated with Eq. (3) (dashed) flow duration curves for the "Senore at Finocchiara" basin (a) and for the "Oreto at Parco" basin (b).

0.05:1, with some critical divergences for extreme streamflows. It is worth to point out that in this study almost the whole range of duration is studied and represented while previous works considered only restricted ranges of durations. For example Fennessey and Vogel (1990) used the range 0.50:0.99 or Castellarin et al. (2004) similarly analyzed the range 0.30:0.99.

As performance index, the root mean square error (RMSE) has been evaluated and normalized by the mean daily streamflow. This performance index, equal to 0.24 for case (a) and equal to 0.15 for case (b) is listed in Table 2 together with the model parameters calculated for the 50 considered basins. This index is largely influenced by the hydrological behavior of the catchments, in fact it goes up to 0.7 for small catchments (less than $200 \mathrm{~km}^{2}$ ) while it decrease to 0.2 for large basins.

\section{The regional model}

Regressive methods have been used to link the three model parameters $\left(D_{\mathrm{w}}, a\right.$ and $\left.b\right)$ to some catchment characteristics such as climatic indexes, geolithologic and geopedologic parameters, land coverage and geomorphic parameters. This analysis has been performed dividing the island into three

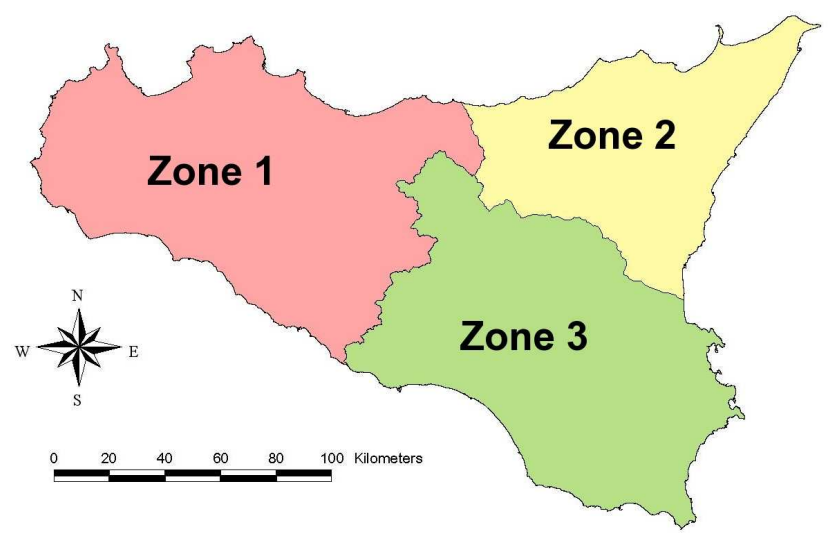

Fig. 4. Sub-zones for parameters regionalization.

sub-zones, as summarized in Fig. 4, using the homogeneous regions suggested by Cannarozzo et al. (1995). The most of the catchments (27) belongs to the sub-Zone 1 which is the Northwestern part of the island where the mean annual rainfall is around $680 \mathrm{~mm}$, close to the regional value. The average area of the basins in this area is $200 \mathrm{kKm}^{2}$, ranging from 10 up to $1186 \mathrm{~km}^{2}$. The sub-Zone 2 has the lower number of stations, but it is also the smallest sub-area. The mean annual rainfall is around $900 \mathrm{~mm}$, higher than the regional value and the basins inside this zone are characterized by relatively small size and steep slopes, especially in the Northeastern part. The sub-Zone 3 is located in the SouthEast part of the island and contains 15 stations. The average annual rainfall equal to $620 \mathrm{~mm}$, is lower than the regional value and the average size of the considered basins is about $300 \mathrm{~km}^{2}$. The homogeneity of these regions has been tested in terms of annual streamflow (Cannarozzo et al., 2009) using the homogeneity test of Hosking and Wallis (1997).

The regressive method used in this study has the following structure:

$\left[D_{\mathrm{w}}, a, b\right]=k_{0}+\sum_{i=1}^{N_{\mathrm{par}}} k_{i} C_{i}$

where $C_{i}$ are the catchment characteristics or their logarithmic transformations and parameters $k_{0}$ and $k_{i}$ are determined through a multiple regression.

Stepwise regression (Hocking, 1976) has been used to select the optimal set of variables reflecting the geomorphological and climatic effects. This method adds additional independent variables one by one, in successive steps, each raising the dimensions of the analysis by one. The most promising independent variable, i.e. the one that provides the greatest reduction in the unexplained variation in the dependent variable ( $D_{\mathrm{w}}, a$ or $\left.b\right)$, is selected at every stage. Then there is a re-examination of all the variables included in the previous steps. A variable that becomes superfluous because of its relationship with other variables in the model is then excluded. 
Table 2. Estimated model parameters and RMSE divided by the mean daily flow. The catchments used for the validation are bolded.

\begin{tabular}{|c|c|c|c|c|c|}
\hline & Catchment & $D_{\mathrm{w}}$ & $a$ & $b$ & RMSE [ ] \\
\hline 1 & Alcantara at Alcantara & 1.00 & 2.584 & 0.714 & 0.083 \\
\hline 2 & Alcantara at Mojo & 0.94 & 0.663 & 0.991 & 0.413 \\
\hline 3 & Alcantara at San Giacomo & 1.00 & 0.192 & 0.749 & 0.224 \\
\hline 4 & Anapo at San Nicola & 1.00 & 0.367 & 0.464 & 0.346 \\
\hline 5 & Asinaro at Noto & 1.00 & 0.195 & 0.437 & 0.168 \\
\hline 6 & Baiata at Sapone & 0.51 & 0.038 & 0.616 & 0.542 \\
\hline 7 & Belice at Sparacia & 0.96 & 0.227 & 0.765 & 0.592 \\
\hline 8 & Belice at Ponte Belice & 0.98 & 0.938 & 1.009 & 0.344 \\
\hline 9 & Belici at Bruciato & 0.84 & 0.085 & 0.872 & 0.651 \\
\hline 10 & Belici at Marianopoli Scalo & 0.66 & 0.140 & 0.842 & 0.740 \\
\hline 11 & Birgi at Chinisia & 0.67 & 0.164 & 0.951 & 0.643 \\
\hline 12 & Cassibile at Manghisi & 1.00 & 0.390 & 0.291 & 0.130 \\
\hline 13 & Castelbuono at Ponte Vecchio & 0.95 & 0.110 & 1.115 & 0.344 \\
\hline 14 & Castello at Castello & 0.62 & 0.025 & 0.520 & 0.496 \\
\hline 15 & Chitarra at Rinazzo & 0.34 & 0.055 & 0.778 & 0.517 \\
\hline 16 & Eleuterio at Lupo & 0.58 & 0.055 & 0.718 & 0.378 \\
\hline 17 & Eleuterio at Risalaimi & 1.00 & 0.150 & 0.622 & 0.331 \\
\hline 18 & Elicona at Falcone & - & - & - & - \\
\hline 19 & Fastaia at Lachinea & 0.46 & 0.045 & 0.939 & 0.254 \\
\hline 20 & Ficuzza at San Pietro & 0.74 & 0.104 & 0.601 & 0.141 \\
\hline 21 & Flascio at Zarbata & 1.00 & 0.188 & 0.913 & 0.454 \\
\hline 22 & Fiume freddo at Alcamo scalo & 0.73 & 0.221 & 0.893 & 0.487 \\
\hline 23 & Ganci at Regiovanni & 0.92 & 0.079 & 0.788 & 0.383 \\
\hline 24 & Imera Merid. at Cinque archi & 0.98 & 0.454 & 1.064 & 0.196 \\
\hline 25 & Imera Merid. at Capodarso & - & - & - & - \\
\hline 26 & Imera Merid. at Drasi & 0.99 & 1.488 & 0.844 & 0.213 \\
\hline 27 & Imera Merid. at Petralia & 1.00 & 0.245 & 0.640 & 0.223 \\
\hline 28 & Imera Merid. at ponte Besaro & 0.99 & 0.918 & 0.961 & 0.247 \\
\hline 29 & Imera Sett. at Scillato & 1.00 & 0.256 & 0.774 & 0.063 \\
\hline 30 & Isnello at Ponte Grande & 0.90 & 0.093 & 0.818 & 0.268 \\
\hline 31 & Jato at Fellamonica & 0.86 & 0.185 & 0.800 & 0.168 \\
\hline 32 & Martello at Petrosino & 0.90 & 0.264 & 0.977 & 0.721 \\
\hline 33 & Milicia at Milicia & - & - & - & - \\
\hline 34 & Nocella at Zucco & 0.97 & 0.117 & 0.773 & 0.090 \\
\hline 35 (b) & Oreto at Parco & 1.00 & 0.423 & 0.684 & 0.108 \\
\hline 36 & Platani at Passofonduto & 1.00 & 0.902 & 0.860 & 0.162 \\
\hline 37 & San Biagio at Mandorleto & 0.80 & 0.063 & 0.693 & 0.486 \\
\hline 38 & Salso at Monzanaro & 0.64 & 0.239 & 0.918 & 0.321 \\
\hline 39 & Salso at Raffo & 0.84 & 0.085 & 0.836 & 0.243 \\
\hline 40 & Saraceno at Chiusitta & 1.00 & 0.160 & 0.871 & 0.388 \\
\hline 41 & Sciaguana at Torricchia & 0.68 & 0.035 & 0.536 & 0.177 \\
\hline 42 (a) & Senore at Finocchiara & 0.66 & 0.119 & 0.894 & 0.241 \\
\hline 43 & San Leonardo at Monumentale & 0.83 & 0.642 & 1.050 & 0.213 \\
\hline 44 & San Leonardo at Vicari & 0.83 & 0.245 & 1.102 & 0.227 \\
\hline 45 & Salso at Ponte Gagliano & 0.74 & 0.749 & 0.990 & 0.092 \\
\hline 46 & Tellaro at Castelluccio & 0.77 & 0.122 & 0.758 & 0.123 \\
\hline 47 & Timeto at Murmari & 1.00 & 0.173 & 0.837 & 0.267 \\
\hline 48 & Torrente Mulini at Guglielmotto & 1.00 & 0.150 & 0.840 & 0.339 \\
\hline 49 & Torto at Bivio Cerda & 0.71 & 0.300 & 0.941 & 0.118 \\
\hline 50 & Torto at Roccapalumba scalo & 0.88 & 0.081 & 0.861 & 0.604 \\
\hline 51 & Trigona at Rappis & 0.65 & 0.255 & 0.608 & 0.188 \\
\hline 52 & Troina at Serravalle & 0.84 & 0.236 & 1.019 & 0.192 \\
\hline 53 & Valle acqua at Serena & 0.75 & 0.051 & 0.754 & 0.613 \\
\hline
\end{tabular}


Table 3. Regional model parameters for the three Sicilian subzones.

\begin{tabular}{rrrrr}
\hline & & Zone 1 & Zone 2 & Zone 3 \\
\hline \multirow{4}{*}{$D_{\mathrm{w}}$} & $j_{0}$ & -3.98 & -2.47 & -3.41 \\
& $j_{1}$ & 0.093851 & 0.011598 & 0.04256 \\
& $j_{2}$ & 0.669824 & 0.49543 & 0.6338 \\
& $R^{2}$ & 0.7 & 0.82 & 0.5 \\
& $\mathrm{RMSE}$ & 0.1031 & 0.04 & 0.114 \\
& $m_{0}$ & -7.6678 & -18.17 & 0.125 \\
& $m_{1}$ & 0.000835 & 0.0038 & 0.00079 \\
$a$ & $m_{2}$ & 0.471309 & 2.2047 & 0.3857 \\
& $m_{3}$ & 1.07098 & 0.7207 & -0.5773 \\
& $R^{2}$ & 0.9 & 0.85 & 0.95 \\
& $\mathrm{RMSE}$ & 0.07 & 0.34 & 0.09 \\
& & & & \\
& $n_{0}$ & 7.539 & 15.13 & -0.39 \\
& $n_{1}$ & -0.00254 & 0.00136 & -0.00508 \\
& $n_{2}$ & 0.06468 & -0.05059 & 0.053893 \\
$b$ & $n_{3}$ & -0.08887 & -1.11219 & 0.365885 \\
& $n_{4}$ & -1.45199 & -1.5297 & -0.2853 \\
& $R^{2}$ & 0.42 & 0.73 & 0.77 \\
& $\mathrm{RMSE}$ & 0.107 & 0.07 & 0.128 \\
\hline & & & &
\end{tabular}

It has been decided not to use variables explaining less than $5 \%$ of the variance. The use of stepwise regressive analysis has led to the determination of three equations for each subzone, which relate model parameters to the above, mentioned catchment characteristics. In order to give a unique formulation for all the considered sub-zones the following equation types have been chosen:

$D_{\mathrm{w}}=j_{0}+j_{1} \ln (\mathrm{Ar})+j_{2} \ln (R)$

$a=m_{0}+m_{1}(\mathrm{Ar})+m_{2} \ln (R)+m_{3} \ln (\mathrm{CN})$

$b=n_{0}+n_{1}(\%$ perm $)+n_{2} \ln (\mathrm{Ar})+n_{3} \ln (R)+n_{4} \ln (\mathrm{CN})(5 \mathrm{c})$

The regional parameters for the three considered sub-zones are reported in Table 3. The relative duration of wet periods has been related to the catchment area and to the mean annual rainfall. This relation is consistent with the technical experience, which suggests that small basins in arid zones have a more ephemeral behavior than large catchments in humid contexts. Similar kind of relation was also found by Croker et al. (2003), who related the probability of dry periods in Portugal to the mean annual rainfall. The relative duration of wet periods is estimated satisfactorily in the three sub-zones; the best result is obtained in the sub-Zone $2\left(R^{2}=0.82, \mathrm{RMSE}=0.04\right)$ while the lower performance is got in the sub-Zone $3\left(R^{2}=0.50, \mathrm{RMSE}=0.114\right)$.

The parameter $a$ has been linked to the basin area, to the mean annual rainfall and to the mean areal value of Curve Number. This parameter is crucial in determining the scale of the process, which, in turn, is driven by the basin morphology and by climate. In this sense the chosen relation is convincing from a physical point of view. In fact, the more large, humid and impermeable the basins are the higher goes the FDC. Also Fennessey and Vogel (1990) related the scale parameter, which in that case was the $\mu$ parameter of a lognormal distribution, to the basin area obtaining an excellent coefficient of determination (0.99). Smakhtin et al. (1997) used as FDC scale parameter the mean daily discharge relating the last to the catchment area and to the mean annual precipitation. Croker et al. (2003) linked the scale parameter of their model for ephemeral catchments to the mean annual rainfall and to the soil characteristics, explaining about the $63 \%$ of the variance of the streamflow equaled or exceeded for $80 \%$ of wet time. Castellarin et al. (2004) identified similar models relating the $\mu$ parameter of a log-normal distribution to the basin area, to the mean annual net precipitation and to the basin elevation. The model parameter $a$ is really well estimated in all the three sub-zones with a maximum of $R^{2}=0.95$ and $\mathrm{RMSE}=0.09$ in the sub-Zone 3 .

Finally, the parameter $b$, which determines the shape of the FDCs, has been related to the catchment area, to the mean annual rainfall, to the percentage of permeable area and to the mean areal value of Curve Number. Fennessey and Vogel (1990) individuated a simple relation between the shape parameter of their FDC, which was the $\sigma$ parameter of a lognormal distribution, and the average basin elevation with an $R^{2}=0.72$. Also the formulation here proposed contains implicitly a link between $b$ and the average basin elevation because there is a strong correlation between this parameter and the annual rainfall $\left(R^{2}=0.60\right)$. Castellarin et al. (2004) related the $\sigma$ parameter of a log-normal distribution to the permeable portion of the basin area, to the average basin elevation and to the mean annual net precipitation with a Nash and Sutcliffe index (Nash, 1970) of 0.52. The parameter $b$ of the model here proposed is reproduced in acceptable way, with the exception of the sub-Zone $1\left(R^{2}=0.42, \mathrm{RMSE}=0.107\right)$. The regional model has been positively validated using one basin for each sub-zone hidden in the original dataset. The three basins here chosen are representative of the basin size distribution: since there are 15 basins with an area lower than $60 \mathrm{~km}^{2}, 14$ basins with area ranging from 60 to $160 \mathrm{~km}^{2}$ and 14 basins with area greater than $160 \mathrm{~km}^{2}$, one basin within each of these three ranges has been randomly selected. The comparison between empirical and estimated FDCs obtained using the regional model for these three basins are shown in Fig. 5. Notwithstanding there is a slight overestimation of the wet period duration (about 5\%), the fitting is quite good for all the considered cases (the adimensionalized RMSE is equal to $0.24,0.32$ and 0.28 respectively for the sub-zones 1 , 2 and 3 ) even if the observation of Fig. 5b (Elicona at Falcone) points out an important difference between empirical FCD and fitted FCD for sub-Zone 2; this difference is due to the estimation of the coefficient a characterized by a high value of RMSE (see Table 3 - sub-Zone 2 RMSE =0.34). 
This behavior can be explained by the presence of the catchment of Alcantara whose coefficient a (equal to 2.58, see Table 2) is definitely different from the other values of coefficient a (ranging from 0.160 to 0.74 for this sub-zone) and, for this reason, it could be considered an "outlier". The morphology and geology of the Alcantara basin, which is totally different from the other considered basins for the proximity to the Etna volcano, could explain this extremely high value of coefficient a. If this "outlier" is removed, the calibration RMSE associated with the coefficient a decreases from 0.34 to 0.13 ; consequently the agreement between empirical and estimated FDC improves (gray solid line in Fig. 5b) and this is confirmed by the decreasing of the adimensional RMSE relative to the FDC (estimated with the new regional equation without Alcantara at Alcantara basin) from 0.37 to 0.23.

\section{Conclusions}

This paper presents a regional model for estimating flow duration curves in Sicily. The model has three parameters: one for individuating the relative duration of wet periods with non-zero streamflows and two for describing the relative duration of non-zero streamflows in wet periods. These parameters have been calculated for 53 Sicilian catchments. The analyzed basins present different streamflow behaviors (perennial or ephemeral) and cover a large range of morphoclimatic characteristics. The parametric model here proposed is able to reproduce the empirical FDCs in a satisfactory way, with some exceptions for high streamflows, usually not considered in this kind of study.

The model parameters have been linked to peculiar catchment characteristics, such as the area, the mean annual rainfall and the mean areal value of Curve Number. This study considers three sub-zones in the island and, for each subzone calculates the model parameters using a unique formulation.

The model has been validated on one basin for each subzone, hidden in calibration, obtaining satisfactory results in terms of FDC fitting. The simplicity of the model structure and the link with simple morpho-climatic characteristics, also available on a GIS based tool called SIRI, make the proposed model a valuable "first approximation" tool for water resources assessment in ungauged basins in Sicily.

Edited by: S. Grimaldi

\section{References}

Beard, L. R.: Statistical analysis in hydrology, Trans., ASCE, 108, 1110-1160, 1943.

Cannarozzo, M., D'Asaro, F., and Ferro, V.: Regional Rainfall and Flood Frequency-Analysis for Sicily Using the 2-Component Extreme-Value Distribution, Hydrol. Sci. J.-J. Sci. Hydrol., 40, 19-42, 1995.
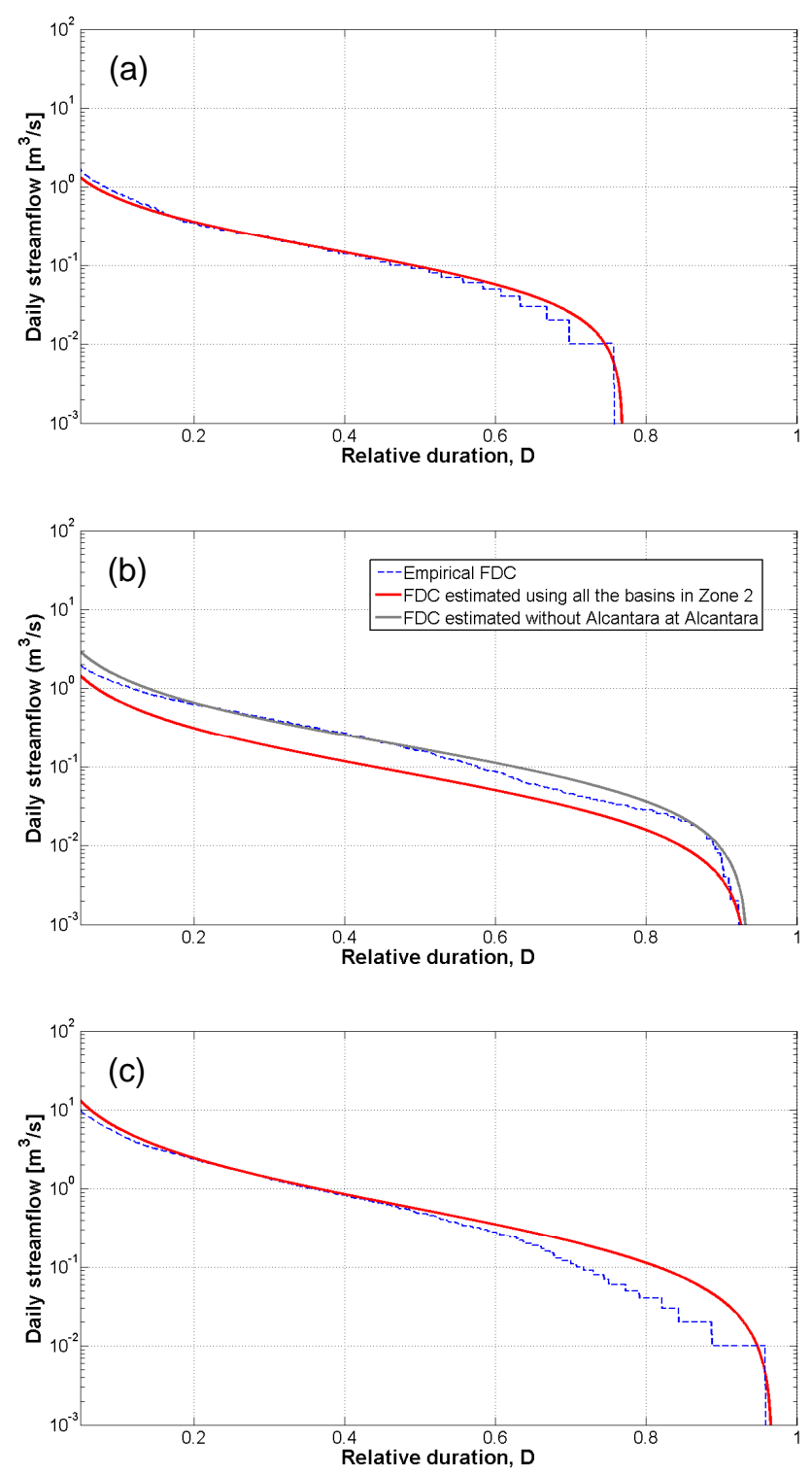

Fig. 5. Comparison between empirical FDCs (dashed line) and FDCs obtained using regional model parameters (red solid line) for the three validation basins inside each sub-zone. (a): Milicia at Milicia within sub-Zone $1\left(D_{\mathrm{w}}=0.76 ; a=0.157 ; b=0.796\right)$; (b) Elicona at Falcone within sub-Zone $2\left(D_{\mathrm{W}}=0.94 ; a=0.088\right.$; $b=0.970$ ), the gray solid line is the FDC estimated with the regional model parameters assessed without Alcantara at Alcantara basin; (c) Imera at Capodarso within sub-Zone $3\left(D_{\mathrm{W}}=0.96 ; a=0.595\right.$; $b=1.059)$.

Cannarozzo, M., Noto, L. V., Viola, F., and La Loggia, G.: Annual runoff regional frequency analysis in Sicily, Physics and Chemistry of the Earth, 34, 679-687, 2009.

Castellarin, A., Galeati, G., Brandimarte, L., Montanari, A., and Brath, A.: Regional flow-duration curves: reliability for ungauged basins, Adv. Water Resour., 27, 953-965, 2004.

Castellarin, A., Camorani, G., and Brath, A.: Predicting annual and 
long-term flow-duration curves in ungauged basins, Adv. Water Resour., 30, 937-953, 2007.

Castrogiovanni, E. M., La Loggia, G., and Noto, L. V.: Design storm prediction and hydrologic modeling using a web-GIS approach on a free-software platform, Atmos. Res., 77(1-4), 367377, 2005.

Croker, K. M., Young, A. R., Zaidman, M. D., and Rees, H. G.: Flow duration curve estimation in ephemeral catchments in Portugal, Hydrol. Sci. J.-J. Sci. Hydrol., 48, 427-439, 2003.

Fennessey, N. and Vogel, R. M.: Regional Flow-Duration Curves for Ungauged Sites in Massachusetts, J. Water Resour. Plan. Manage.-ASCE, 116, 530-549, 1990.

Franchini, M. and Suppo, M.: Regional analysis of flow duration curves for a limestone region., Water Resour. Manage., 10, 199218, 1996.

Ganora, D., Claps, P., Laio, F., and Viglione, A.: An approach to estimate nonparametric flow duration curves in ungauged basins, Water Resour. Rese., 45, W10418, doi:10.1029/2008WR007472, 2009.

Hocking, R. R.: The Analysis and Selection of Variables in Linear Regression, Biometrics, 32, 1-49, 1976.

Hosking, J. and Wallis, J.: Regional Frequency Analysis: An Approach Based on L-Moments, Cambridge Univ. Press,, New York, 1997.

Iacobellis, V.: Probabilistic model for the estimation of $\mathrm{T}$ year flow duration curves, Water Resour. Res., 44, W02413, doi:10.1029/2006WR005400, 2008.

Leboutillier, D. W. and Waylen, P. R.: Regional Variations in FlowDuration Curves for Rivers in British-Columbia, Canada, Phys. Geogr., 14, 359-378, 1993.

Nash, J. E. and Sutcliffe, J.V.,: River flow forecasting through conceptual models, 1. A discussion of principles., J. Hydrol., 10, 282-290, 1970.
Niadas, I. A.: Regional flow duration curve estimation in small ungauged catchments using instantaneous flow measurements and a censored data approach, J. Hydrol., 314, 48-66, 2005.

Noto, L., La Loggia, G., and Pirrello, M.: Un Sistema Informativo Territoriale per l'analisi del rischio idraulico delle infrastrutture viarie, 5a Conferenza Nazionale ASITA, Rimini, Italy, 2001,

Noto, L. V. and La Loggia, G.: Use of L-Moments Approach for Regional Flood Frequency Analysis in Sicily, Italy, Water Resour. Manage., 23, 2207-2229, 2009.

Quimpo, R., Alejandrino, A., and McNally, T.: Regionalised flow duration curves for Philippines., J. Water Resour. Plann. Manage. ASCE, 109(4), 320-330, 1983.

Singh, R. D., Mishra, S. K., and Chowdhary, H.: Regional flowduration models for large number of ungauged Himalayan catchments for planning microhydro projects, J. Hydrol. Eng., 6, 310316, 2001.

Smakhtin, V. U.: Low flow hydrology: a review, J. Hydrol., 240, 147-186, 2001.

Smakhtin, V. Y., Hughes, D. A., and Creuse-Naudin, E.: Regionalization of daily flow characteristics in part of the Eastern Cape, South Africa, Hydrol. Sci. J.-J. Sci. Hydrol., 42, 919-936, 1997.

Thornthwaite, C. W.: An approach toward a rational classification of climate, Geographical Review, 38(1), 55-94, 1948.

Vogel, R. M. and Fennessey, N. M.: Flow-Duration Curves 2. New Interpretation and Confidence-Intervals, J. Water Resour. Plan. Manage.-ASCE, 120, 485-504, 1994.

Vogel, R. M. and Fennessey, N. M.: Flow Duration Curves 2. a Review of Applications in Water-Resources Planning, Water Resour. Bull., 31, 1029-1039, 1995.

Yu, P. S., Yang, T. C., and Wang, Y. C.: Uncertainty analysis of regional flow duration curves, J. Water Resour. Plan. Manage.ASCE, 128, 424-430, 2002. 